\title{
Fungos endofíticos de Eugenia dysenterica DC como biocontroladores de fitopatógenos in vitro
}

\author{
Camilla Martins MALTA ${ }^{[1 ; *}$; Eskálath Morganna Silva FERREIRA ${ }^{[1]}$; Cristiane Martins COELHO ${ }^{[1]}$, Raphael Sanzio \\ PIMENTA ${ }^{[2]}$ \\ ${ }^{[1]}$ Universidade Federal do Tocantins, Campus Palmas. Laboratório de Microbiologia geral e Aplicada. Avenida NS 15, 109 Norte - Plano Diretor \\ Norte, 77001-090. Palmas-TO, Brasil. Email: camillamalta_17@hotmail.com, morganna_ferreira@hotmail.com, criscoelho@uft.edu.br \\ ${ }^{[2]}$ Professor do programa de Pós-Graduação Doutorado em Biodiversidade e Biotecnologia da Amazônia Legal (BIONORTE). Laboratório de \\ Microbiologia geral e Aplicada. Avenida NS 15, 109 Norte - Plano Diretor Norte, 77001-090. Palmas-TO, Brasil. E-mail: biorapha@yahoo.com.br
}

\begin{tabular}{|c|c|}
\hline INFORMAÇÕES & RESUMO \\
\hline Recebido em: 07/09/2015 & \multirow{12}{*}{$\begin{array}{l}\text { Os micro-organismos antagonistas (bactérias, leveduras e fungos filamentosos) têm } \\
\text { a capacidade de exercer um efeito antagonista sobre diferentes patógenos sendo } \\
\text { empregados para controlar diversas enfermidades de frutos e vegetais. Este estudo } \\
\text { objetivou isolar e testar microrganismos presentes em Eugenia dysenterica DC } \\
\text { contra Aspergillus parasiticus, Colletotrichum gloeosporioides e Monilinia } \\
\text { fructicola e in vitro. Foram coletados caules e folhas de } 30 \text { indivíduos de } \\
\text { Cagaiteira. Os fragmentos vegetais passaram por desinfecção superficial, de acordo } \\
\text { com o proposto por Rosa, et. al, }(2010) \text {. Os fragmentos foram inoculados em placas } \\
\text { de Petri contendo ágar Batata a } 25-28{ }^{\circ} \mathrm{C} \text { por um período de até } 60 \text { dias. Os } 263 \\
\text { endofíticos obtidos foram purificados e avaliados quanto ao seu potencial de } \\
\text { inibição por produção de substâncias difusíveis e voláteis. Um total de } 96 \text { dos } \\
\text { isolados, demonstraram atividade antagonista contra os fitopatógenos. Sendo } 45 \\
\text { isolados capazes de inibir o crescimento do fitopatógeno A. parasiticus. Contra o } \\
\text { fitopatógeno C. gloeosporioides } 68 \text { endofíticos apresentaram atividade antagonista. } \\
\text { Já contra o fitopatógeno } M \text {. fructicola apenas } 17 \text { fungos foram capazes de exercer } \\
\text { efeito inibitório. Os isolados obtidos apresentaram potencial para produção de } \\
\text { substâncias bioativas contra estes fitopatógenos. }\end{array}$} \\
\hline $6 / 11 / 2015$ & \\
\hline Publicado & \\
\hline Document Object Identifier & \\
\hline 10.18 & \\
\hline Termos de indexação: & \\
\hline Eugenia dysenterica DC & \\
\hline agons & \\
\hline Endofíticos & \\
\hline fitopatógenos & \\
\hline *Autor para correspondência & \\
\hline & \\
\hline
\end{tabular}

\section{Endophytic fungi Eugenia dysenterica DC as biocontrol of plant pathogens in vitro.}

\begin{abstract}
The antagonistic microorganisms (bacteria, yeasts and filamentous fungi) are able to exert an antagonistic effect on various pathogens being used to control various diseases of fruits and vegetables. This study aimed to isolate and test microorganisms present in Eugenia dysenterica DC against Aspergillus parasiticus, Colletotrichum gloeosporioides, and Monilinia fructicola and in vitro. Stems and leaves were collected from 30 specimens of cagaiteira. The samples were submited to a surface disinfection, according to the proposed by Rose, et. al, (2010). Fragments were inoculated on Petri plates containing the agar Potato $25-28{ }^{\circ} \mathrm{C}$ for 60 days. 263 endophytic fungi strains were obtained, purified and assessed for their potential in to produce inhibitore volatile or diffusible substances. A total of 96 isolates showed antagonistic activity against plant pathogens. 45 isolates being able to inhibit the growth of A. parasiticus. Against the pathogen $C$. gloeosporioides 68 endophytes showed antagonist activity. Against the pathogen $M$. fructicola only 17 fungi were able to exert inhibitory effect. These isolates showed potential for the production of bioactive substances against these pathogens.
\end{abstract}

Index terms: Eugenia dysenterica DC, antagonism, endophytic, phytopathogens

c) (i) (2)(-) Copyright: (C) 2015 JBFS all rights. This is an open-access article distributed under the terms of the Creative CY No SA Commons Attribution License, which permits unrestricted use, distribution, and reproduction in any medium, provided the original author and source are credited.

Financiamento: Os autores reportam que não houve suporte e auxílio financeiro.

Conflito de interesse: Os autores declaram que não há conflito de interesse.

Como referir esse documento (ABNT):

MALTA, C. M.; FERREIRA, E. M. S.; COELHO, C. M.; PIMENTA, R. S. Fungos endofíticos de Eugenia dysenterica DC como biocontroladores de fitopatógenos in vitro. Journal of Bioenergy and Food Science, Macapá, v.2, n.4, p.189-193, out./dez., 2015. http://dx.doi.org/10.18067/jbfs.v2i4.68 


\section{INTRODUÇÃO}

Entre as espécies de frutas comestíveis nativas do cerrado a cagaita ou cagaiteira - Eugenia dysenterica DC - é altamente apreciada pela população. Tem uma ampla distribuição no cerrado, ocorrendo nos Estados da Bahia, Goiás, Maranhão, Mato Grosso, Mato Grosso do Sul, Minas Gerais, Pará, Piauí, São Paulo, Tocantins e Distrito Federal [1].

Evolutivamente, as plantas vêm desenvolvendo complexos mecanismos adaptativos, sendo que o estabelecimento das mesmas em seus respectivos habitats envolve a sua capacidade em interagir com diferentes espécies de seres vivos [2]. Fungos endofíticos podem estar presentes em todos os órgãos de uma planta hospedeira, podendo sua colonização se dar de forma inter ou intracelular, localizada ou sistêmica [3]. Segundo Gundel et al. [4], os endófitos frequentemente induzem alterações morfológicas, fisiológicas e bioquímicas em seus hospedeiros, o que pode afetar a performance das plantas sob diferentes estresses bióticos ou abióticos, tais como déficit hídrico, salinidade e altas concentrações de metais no solo, herbicidas e herbívoros. Assim, estes microrganismos podem ser benéficos aos hospedeiros ao conferir resistência a insetos e herbívoros, tolerância à dessecação, proteção contra patógenos e, ainda, aumentar o crescimento vegetativo [2].

Microrganismos endofíticos são potencialmente úteis na agricultura e na indústria, particularmente na alimentícia e farmacêutica. Podem ser utilizados como vetores para introdução de genes de interesse nas plantas, como agentes inibidores de pragas e patógenos, e como fontes de metabólitos primários e secundários de interesse como o taxol, poderoso anticancerígeno e a cryptocandina, lipopeptídeo antimicótico e diversos outros antimicrobianos [5].

A seleção de antagonistas da microbiota residente no fruto pode ter vantagens ecológicas sobre antagonistas casualmente depositados no fruto ou aqueles que residem principalmente no solo. Estes antagonistas também podem ser mais aceitáveis no tratamento pós-colheita de frutas com ampla aceitação e consumo, uma vez que são consumidos juntamente com os frutos durante anos sem efeitos adversos conhecidos [6].

As doenças de plantas são responsáveis por grandes perdas nas culturas de importância econômica, principalmente aquelas que ocorrem durante a pós-colheita. Os fungos são os principais causadores de doenças pós-colheita em frutas. Aspergillus flavus e Aspergillus parasiticus, contaminam numerosos alimentos em climas quentes onde podem produzir aflatoxinas em diferentes pontos da cadeia, como pré-colheita, processamento, transporte ou armazenamento [7].

Os fungos do gênero Colletotrichum apresentam as espécies que estão entre os mais bem sucedidos fungos patogênicos de plantas, causando significativos prejuízos econômicos às plantações das regiões tropicais, subtropicais e temperadas [8]. C. gloeosporioides é o mais expressivo agente causador da antracnose, principal doença de frutos em pós-colheita, e pode degradar: banana (Musa spp.), caju (Anacardium occidentale L.), goiaba (Psidium guajava), manga (Mangifera indica L.), mamão (Carica papaya L.), maracujá (Passiflora edulis f. flavicarpa Deg.), entre outras [9].

Monilinia fructicola é responsável pela podridão parda, a qual constitui a doença mais importante das frutas de caroço, como o pêssego, representando também significativas perdas para a economia mundial [10]. A podridão parda pode ser causada por três espécies do gênero Monilinia, $M$. fructicola (G. Winter) Honey, M. laxa (Aderhold \& Ruhland) Honey e M. fructigena (Aderh. \& Ruhl) Honey. Na América do Sul e do Norte, Índia, Japão, República da Coréia, Oceania encontram-se as espécies M. fructicola e M. laxa e na Europa, $M$. fructigena $[11,12]$.

Portanto, este estudo teve como objetivo, contribuir para o conhecimento da microbiota endofítica e epifítica associada à Eugenia dysenterica DC (cagaita) e avaliar o potencial dos mesmos na produção de metabólitos com atividade antimicrobiana. Somando assim, conhecimentos às metodologias já estabelecidas e apontar novas estratégias de controle biológico de fitopatógenos.

\section{MATERIAL E MÉTODOS}

\section{a) Obtenção dos Endofíticos}

Foram coletadas amostras de folhas e de caule de 30 indivíduos de Cagaiteira, provenientes da região ecotonal entre áreas de cerrado e de pastoreio, na Fazenda Suécia, localizada na rodovia estadual TO $010 \mathrm{Km} 16$ e regiões circunvizinhas. As amostras de caules e folhas, foram armazenadas em sacos plásticos e posteriormente processadas no Laboratório de Microbiologia Ambiental e Biotecnologia da Universidade Federal do Tocantins.

Os fragmentos de caules foram cortados com tesoura estéril e os fragmentos de folhas foram obtidos através de cortes realizados com perfurador de rolha estéril. Os fragmentos passaram então por desinfecção superficial, através da imersão em álcool $70 \%$ (por $1 \mathrm{~min}$.), hipoclorito de sódio $2 \%$ 
(por 3 min.) e água destilada estéril (por 2 min.) [13].

Após a desinfecção superficial, os fragmentos foram transferidos para placas de Petri contendo ágar BDA (Batata Dextrose Ágar), suplementado com cloranfenicol $(100 \mu \mathrm{g} / \mathrm{mL})$. As placas foram inoculadas com 3 fragmentos de caule ou folha, sendo a amostragem por indivíduo vegetal realizada em triplicata. Ou seja, três placas com 3 fragmentos de caule cada e três placas com 3 fragmentos de folhas. Totalizando 9 fragmentos de caule e 9 fragmentos de folhas para cada indivíduo de cagaita amostrado. Em seguida as placas foram incubadas a $25-28{ }^{\circ} \mathrm{C}$ por um período de até 60 dias. Os isolados fúngicos obtidos após a incubação foram individualmente transferidos para novas placas de Petri contendo BDA e incubados a $25-28^{\circ} \mathrm{C}$ por 7 dias para purificação.

\section{b) Preparação dos inóculos}

Os isolados endofíticos e os fitopatógenos, Aspergillus parasiticus (IMI 242698) - cepa gentilmente cedida pelo Instituto de Micologia da Inglaterra, Colletotrichum gloeosporioides (CG INCOPER 02) e Monilinia fructicola (MFA 3635), foram previamente cultivados em ágar BDA (Batata Dextrose Ágar) durante 7 dias.

\section{c) Antagonismo in vitro}

Para a verificação da produção de substâncias difusíveis, um disco de ágar de 6 milímetros de diâmetro contendo micélio de cada fungo endofítico foi inoculado em um lado de uma placa de Petri contendo meio BDA e incubado por três dias a 25$28^{\circ} \mathrm{C}$. Em seguida, um disco similar de cada fitopatógeno foi inoculado no lado oposto da placa. Após três dias de incubação a $25-28^{\circ} \mathrm{C}$, o diâmetro do micélio fúngico dos fitopatógenos foram medidos com auxílio de paquímetro digital e comparados com as dimensões do controle. $\mathrm{O}$ teste de produção de substâncias voláteis foi realizado utilizando-se a mesma metodologia, porém o meio de cultivo foi dividido ao meio com o auxílio de lâmina de bisturi estéril, a fim de evitar o efeito de difusão. Estas placas foram seladas com parafilme, e incubadas nas mesmas condições utilizadas para o teste de substâncias difusíveis.

Os controles negativos foram realizados com a inoculação de cada fitopatógeno no meio de cultura sem o antagonista. Foram considerados ativos os fungos endofíticos que inibiram o crescimento de pelo menos um dos fitopatógenos alvos em um valor igual ou superior a $50 \%$ comparando-se com o diâmetro das colônias do controle.

\section{RESULTADOS E DISCUSSÃO}

Após o processo de isolamento e purificação, foram obtidos 263 isolados, para os testes seguintes. Sendo 147 colônias provenientes de folhas e 116 de caules de Eugenia dysenterica DC.

Todos os 263 endofíticos isolados foram avaliados quanto ao seu potencial contra os fitopatógenos A. parasiticus (IMI 242698), $C$. gloeosporioides (CG - INCOPER 02) e $M$. fructicola (MFA 3635). Sendo que 96 dos isolados, ou seja $36,5 \%$, demonstraram atividade antagonista contra pelo menos um dos fitopatógenos alvo. Dos antagonistas positivos 31 endófitos (32,2 \%) produziram substâncias voláteis, $42 \quad(43,7 \%)$ produziram substâncias difusíveis e $23(23,9$ \%) produziram ambas as substâncias (Figura 1).

Figura 1. Relação de números de endofíticos antagonistas quanto as substâncias produzidas.

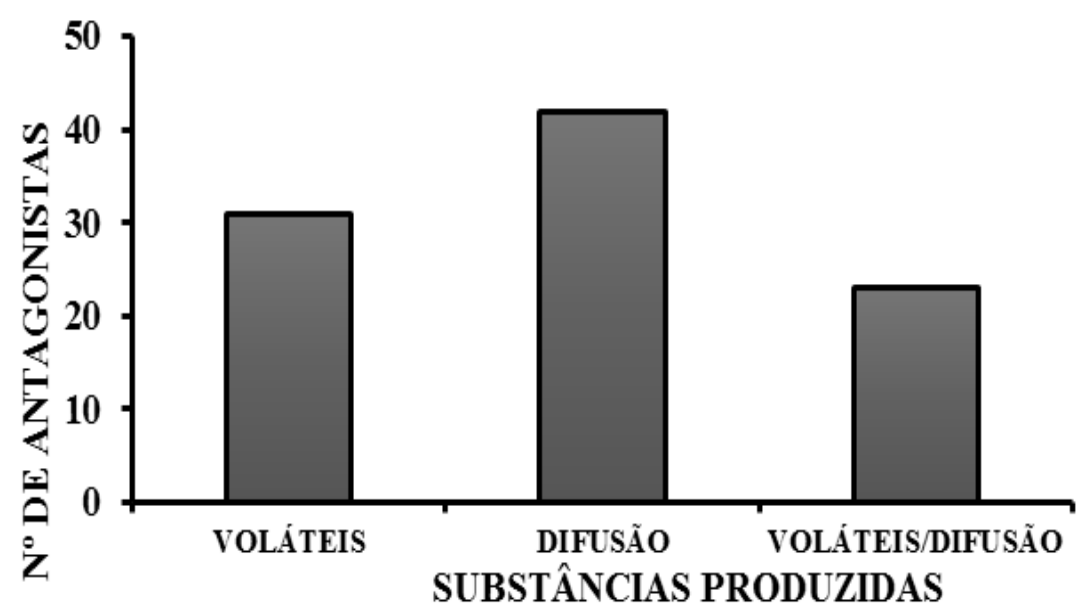


Dos 96 indivíduos endofíticos que apresentaram atividade antagonista, 45 (46,8 \%) foram capazes de inibir o crescimento de $A$. parasiticus (IMI 242698). Sendo que destes, 17 isolados foram antagonistas produzindo substâncias voláteis, 21 produzindo substâncias difusíveis e 6 produziram ambas as substâncias.

Contra C. gloeosporioides (CG - INCOPER 02) 68 isolados $(70,8 \%)$ apresentaram atividade antagonista. Sendo a inibição observada através da produção de substâncias voláteis de 14 isolados, substâncias difusíveis de 36 exemplares fúngicos e 18 endófitos produziram as duas substâncias em ambos os testes.

Já contra o fitopatógeno $M$. fructicola (MFA 3635) apenas 17 fungos foram considerados positivos $(17,7 \%)$. Sendo que 9 isolados produziram substâncias voláteis, 5 através da produção de substâncias difusíveis e apenas 3 indivíduos produziram ambas as substâncias (Figura 2).

Figura 2. Frequência de fungos filamentosos provenientes de Eugenia dysenterica DC antagonistas contra os fitopatógenos Aspergillus parasiticus, Colletotrichum gloeosporioides e Monilinia fructicola.

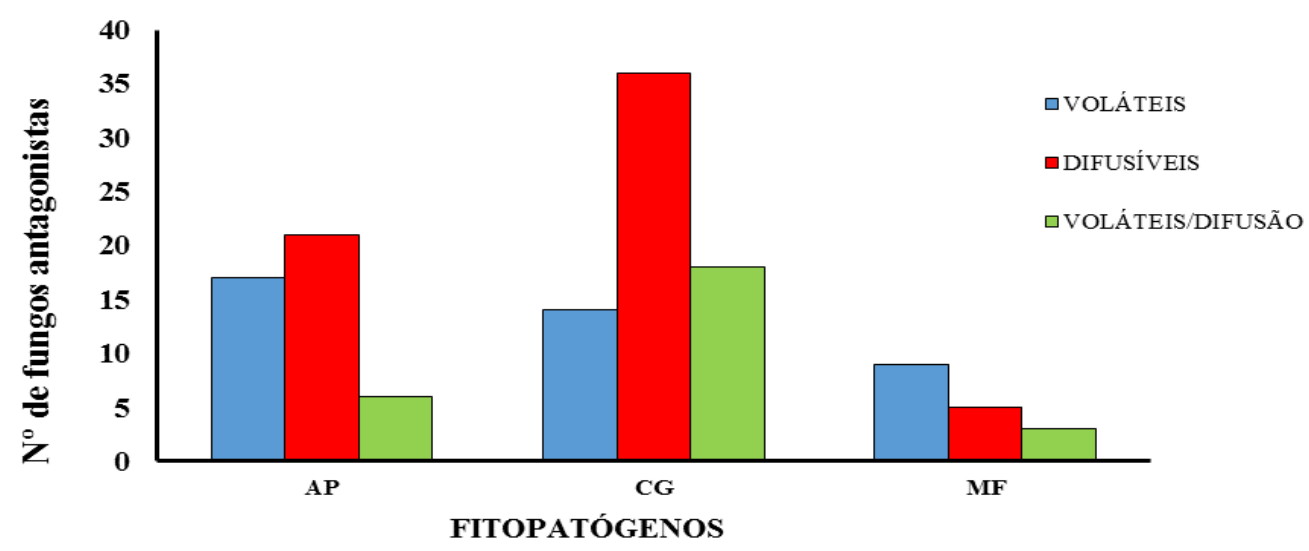

No presente estudo foi observado um grande número de isolados capazes de inibir o crescimento de A. parasiticus e C. gloeosporioides. Em contraste, foi observada uma baixa frequência de isolados ativos contra M. fructicola, assim como em trabalho realizado por Turibio [14]. Onde fungos endofíticos isolados de soja (Glycine max (L) Merril) foram testados como inibidos do crescimento dos fitopatógenos A. parasiticus, $C$. gloeosporioides e M. fructicola. Dentre os 140 isolados testados quanto à produção de substâncias difusíveis no meio, 1 inibiu o crescimento de $A$. parasiticus, 12 inibiram C. gloeosporioides e 1 inibiu o crescimento micelial de $M$. fructicola. Um isolado foi ativo tanto para $A$. parasiticus quanto $M$. fructicola. No teste de produção de compostos voláteis bioativos, 3 isolados foram ativos exclusivamente contra A. parasiticus, 1 exclusivamente contra $M$. fructicola e 8 também exclusivos, contra C. gloeosporioides. Sendo que, 4 fungos apresentaram atividade contra os patógenos M. fructicola e C. gloeosporioides simultaneamente.

A baixa frequência de endófitos antagonistas para $M$. fructicola pode ser justificada pela influência da pressão evolutiva sobre $A$. parasiticus e C. gloeosporioides, fitopatógenos que ocorrem em várias regiões do Brasil, e pela ausência ou inexpressiva pressão seletiva sobre o segundo, de ocorrência menos frequente em nosso país [15, 16].

\section{CONCLUSÃO}

E. dysenterica mostrou ser um importante hospedeiro vegetal, constituindo uma boa fonte de fungos endofíticos.

Os isolados fúngicos apresentaram grande potencial para biocontrole dos fitopatógenos $A$. parasíticos e C. gloeosporioides, através da produção de substâncias bioativas (difusíveis e voláteis).

\section{CONTRIBUIÇÃO DOS AUTORES}

1. Condução e avaliação do experimento, análises estatísticas e elaboração do artigo:

Camilla Martins Malta

\section{Eskálath Morganna Silva Ferreira}

Cristiane Martins Coelho

2. Planejamento, orientação e revisão final do artigo:

Dr. Raphael Sanzio Pimenta

Camilla Martins Malta 


\section{REFERÊNCIAS}

[1]. OLIVEIRA, M. E. S.; PANTOJA, L.; DUARTE, W. F.; COLLELA, C. F.; VALARELLI, L. T.; SCHWAN R. F.; DIAS, D. R. Fruit wine produced from cagaita (Eugenia dysenterica $\mathrm{DC}$ ) by both free and immobilized yeast cell fermentation, Food Research International. Food Research International. v.44, p.2391-2400, 2011. http://dx.doi.org/10.1016/j.foodres.2011.02.028

[2]. PINTO, W. S.; ROSA L. H.; SILVA, J. F. M.; PERIM M. C.; BORGES, J. C.; JANIEWICZ, W. J. PIMENTA, R. S. Diversity and antimicrobial activities of endophytic fungi isolated from Myrcia sellowiana in Tocantins, Brazil. International Worshop on Biological Control of Postharvest Diseases: Challenges and Opportunities, 2010.

[3]. Guimarães, D. O. Prospecção química e biológica em fungos endofíticos associados a Vigueira arenaria (Asteraceae) 2006. $208 \mathrm{f}$. Dissertação de Mestrado - Faculdade de Ciências Farmacêuticas de Riberão Preto, Universidade de São Paulo, Riberão Preto, 2006.

[4]. GUNDEL, P. E.; MARTÍNEZ-GHERSAL, M. A.; BATISTA, W. B.; GHERSA, C. M. Dynamics of Neotyphodium endophyte infection in ageing seed pools: incidence of differential viability loss of endophyte, infected seed and non-infected seed. Annals of Applied Biology, p.199-209, 2010. http://dx.doi.org/10.1111/j.1744-7348.2009.00379.x

[5]. GUIMARÃES, D. O. Produtos naturais de fungos endofíticos associados a espécies de Asteraceae e ensaio antibiótico no modelo de infeccção em Caenorhabditis elegans. 2009. 186f. Tese. Faculdade de Ciências Farmacêuticas de Riberão Preto - Universidade de São Paulo, Ribeirão Preto, 2009.

[6]. JANISIEWICZ, W. J; KURTZMAN, C. P.; BUYER, J. S. Yeasts associated with nectarines and their potential for biological control of brown rot. Yeast. $\quad$ v.27, p.389-398, 2010. http://dx.doi.org/10.1002/yea.1763

[7]. SARDIÑAS, N.; VÁZQUEZ, C.; GIL-SERNA, J.; GONZÁLEZ-JAÉN, M. T.; PATIÑO, B. Specific detection and quantification of Aspergillus flavus and Aspergillus parasiticus inwheat flour by SYBR ${ }^{\circledR}$ Green quantitative PCR. International Journal of Food Microbiology. v. 145, p. 121-125, 2011. http://dx.doi.org/10.1016/j.ijfoodmicro.2010.11.041

[8]. BAILEY, A. J.; JEGER, J. M. Colletotrichum: biology, pathology and control. Oxford: British Society for Plant Pathology, p. 388, 1992.

[9]. ROZWALKA, L. C.; LIMA, M. L. R. Z. C.; MIO, L. L. M.; NAKASHIMA, T. Extracts, decoctions and essential oils of medicinal and aromatic plants in the inhibition of Colletotrichum gloeosporioides and Glomerella cingulata isolates from guava fruits. Ciência Rural, Santa Maria, v.38, n.2, mar-abr, p.301-307, 2008. http://dx.doi.org/10.1590/S0103$\underline{84782008000200001}$

[10]. MOREIRA, L. M.; MAY-DE MIO, L. L. Controle da podridão parda do pessegueiro com fungicidas e fosfitos avaliados em pré e pós-colheita. Ciênc. Agrotec., v. 33, n. 2, p. 405-411, 2009. http://dx.doi.org/10.1590/S1413$\underline{70542009000200007}$

[11]. CASARIN, J. V. Avaliação da variabilidade de espécies de Monilinia associadas à podridão parda do pêssego. 2007. 56 f. Dissertação (Mestrado em Fitossanidade) Setor de Fitopatologia, Universidade Federal de Pelotas, Pelotas

[12]. CASALS, C.; TEIXIDÓ, N.; VINAS, I.; LLAURADÓ, S.; USALL, J. Control of Monilinia spp. on stone fruit by curing treatments Part I. The effect of temperature, exposure time and relative humidity on curing efficacy. Postharvest Biology and Technology, v. 56, p. 19-25, 2010. http://dx.doi.org/10.1016/j.postharvbio.2009.11.008

[13]. ROSA L. H.; GONÇALVES, V. N.; CALIGIORNE R. B.; ALVES T. M. A.; RABELLO, A.; SALES P. A.; ROMANHA, A. J.; SOBRAL M. E. G.; ROSA, C. A.; ZANI, C. L. Leishmanicidal, trypanocidal, and cytotoxic activities of endophytic fungi associated with bioactive plants in Brazil. Brazilian Journal of Microbiology. v. 41, p. 420430, 2010. http://dx.doi.org/10.1590/S1517$\underline{83822010000200024}$

[14]. TURIBIO, T. O. Verificação da produção de substâncias bioativas a partir de fungos endofíticos isolados da Soja, Glycine $\max L$. Merril contra patógenos humanos e vegetais. Dissertação de mestrado. Universidade Federal do Tocantins, Porto Nacional, 2011

[15]. FORTES, J. F. Principais doenças. In: RASEIRA, M. DO C. B.; CENTELLAS QUESADA, A. (Ed.). Pêssego: produção. BrasíliaDF: Embrapa Informação Tecnológica, 2003. p.107-114 (Frutas do Brasil, 49).

[16]. PIMENTA, R. S.; DA SILVA, J. F. M.; BUYER, J. S.; JANISIEWICZ, W. J. Endophytic Fungi from Plums (Prunus domestica) and Their Antifungal Activity against Monilinia fructicola. Journal of Food Protection, v. 75, p. 1883-1889, 2012. http://dx.doi.org/10.4315/0362-028X.JFP-12$\underline{156}$ 